\title{
Gender Differences and Adjustment of Rural Elderly
}

\author{
${ }^{1}$ Debasmita Barik and ${ }^{2}$ Dr. (Prof.) Bharati Panda \\ Research Scholar \& Professor \\ ${ }^{1,2}$ Post Graduate Department of Home Science Sambalpur University, Jyoti Vihar, Burla-768 019, Sambalpur, \\ Odisha, India
}

\begin{abstract}
The number of older person rising in the country as consequences, there are certain problems in different region and cultures. Adjustment is a common psychiatric problem in old age. It is difficult to adjustment due to limited capacity, lower mental abilities and increased economic dependency in old age. The present investigation is an attempt to study the gender differences and adjustment of elderly. The sample comprised of 100 elderly people (50 male and 50 female) of rural area of Kendujhar district, Odisha in the age group of 60 - 75 years. Random sampling technique was used for sample selection, Shamshad - Jasbir - old age adjustment inventory was used to measure the adjustment level of elderly. Interview method was used for collection of data. The data were analysed by employing $t$ test in SPSS (16.0). The findings of the study shows that the male elderly have higher adjustment in the area of health, home, social, marital, emotional and financial than the female elderly.
\end{abstract}

Key Words: Adjustment, gender, old age

\section{Introduction}

Aging is a main concern in the $21^{\text {st }}$ century. The proportion of world's older population has increased because of lower fertility, improved health and longevity (Trivedi et al., 2006). United Nations report states that the population of aged growing at faster rate (3.4 times) in the developing region than in the developed region (1.84 times of the world). India is a most populous nation, have 38 percent of the world's elderly. The population of older persons (60+) has constantly been rising since the first census in independent India in 1951. Population of aged (60+) in the total population of India was around 5.5 percent that increased to nearly 6 percent in 1971 and almost 5 percent in 2001. The number of such population has increased from nearly 20 million in 1951 to 77 million in 2001 (Verma, 2011) and almost 100 million in 2011 (Agewell study, 2011).

As the number of older people rising in the country there are certain problems in different cultures and region (Kapoor et al., 2000). Problems of aged can be varying in nature such as biological, psychological, social or economic. Earlier in the traditional joint family structure the aged considered as the asset of family and society. They enjoyed high power, prestige and decision making responsibilities in the economic, political and social activities of the family. But in last few decades, the researches shows that the changing socio - economic scenario, industrialization, urbanization and modernization have change the values of joint family (Sivaraju, $2000,2002,2004)$ as a result the old person have little or no authority in the new families of their children (Shettar, etal., 2011). Moreover, in rural areas people mostly dependent on agriculture and allied occupation so economic dependency is very common in later years of their life. Further it is seen that the higher percentage of women have been housewives throughout their life and feeling of economic insecurities has been more pronounced among them (Capoor, 2008).

Adjustment in psychology involves both mental and behavioural process by which a person maintains an equilibrium with their needs and the obstacles imposed upon him by the environments. A number of adjustments begin when it is felt and end when it is satisfied. Generally it is difficult to adjustment in old age due to diminishing health, limited capacity, lower mental abilities and increased economic dependency (Shukla et al., 2013). Moreover, it is a period of transition where one has to face set of changes, expectations and also do several compromises (Nema, 2013). A study carried out by Bhatacharya etal. (2013) on 200 elderly people who were living in nuclear family of Calcutta city and result revealed that gender, age and family income has significant relation with adjustment of elderly. Elderly between 65-70 female and having higher family income were better adjustment than 71-75 male and low family income.

The women in India have a lower education, income and authority within the family than man. They are more prone to disadvantaged in old age. On this basis Rajasekhar (2013) made an attempt to study the familial relationship of 250 elderly women of above 60 years in rural Andhrapradesh. It is observed that the increasing proportion of elderly women have not good relation with their son and daughter-in-law, in addition they are mostly considered as burden in lower socio economic group. 
Narang etal., (2013) carried out a study on 50 samples in the age group of 65 years and above who were living with their spouse, children and grandchildren. The researcher also studied on the family members of the sample and found the satisfactory interpersonal relationship within the family, because of love, affection between the family members.

\section{Methodology:}

The sample of the study consisted of 100 elderly in the age group of $60-75$ years (50 male and 50 female) from five villages (Turumunga, Jharbeda, Dimiriguda, Kainda and Tribindha) of Kendujhar district, Odisha, in the eastern part of India. Random sampling technique was used for sample selection, Shamshad Jasbir - old age adjustment inventory developed by Shamshad Hussain and Jasbir Kaur (1995) was used to measure the adjustment level of elderly. Interview method was used for collection of data. The data were analyzed by percentage distribution, mean and statistical $t$ test employed to know the difference between mean in SPSS (16.0). The exclusion criteria was participants with a severe health problem, with no children, remarried, having own parents, difficulties in understanding the guidelines and those not interested for consent. Participants included for the study were person's living with spouse, children, grandchildren, daughter-in-law, spouse alone, widowed living with children and children living in nearer or far place to the house.

Table 1: Percentage distribution of elderly by sex and educational status

\begin{tabular}{|c|c|c|c|c|}
\hline Educational status & \multicolumn{2}{|l|}{ Male } & \multicolumn{2}{|c|}{ Female } \\
\hline & $\mathrm{N}=50$ & $\%$ & $\mathrm{~N}=50$ & $\%$ \\
\hline Illiterate & 3 & 6 & 16 & 32 \\
\hline Up to primary Level & 11 & 22 & 19 & 38 \\
\hline Up to Matric Level & 28 & 56 & 13 & 26 \\
\hline Up to Intermediate level & 2 & 4 & 1 & 2 \\
\hline Graduation and above & 6 & 12 & 1 & 2 \\
\hline
\end{tabular}

Table1 shows that majority of female elderly were illiterate (32\%) and up to primary level (38\%) whereas only $6 \%$ male were illiterate, $56 \%$ up to matric level of education. It shows $12 \%$ male were graduated and above qualification while $2 \%$ female.

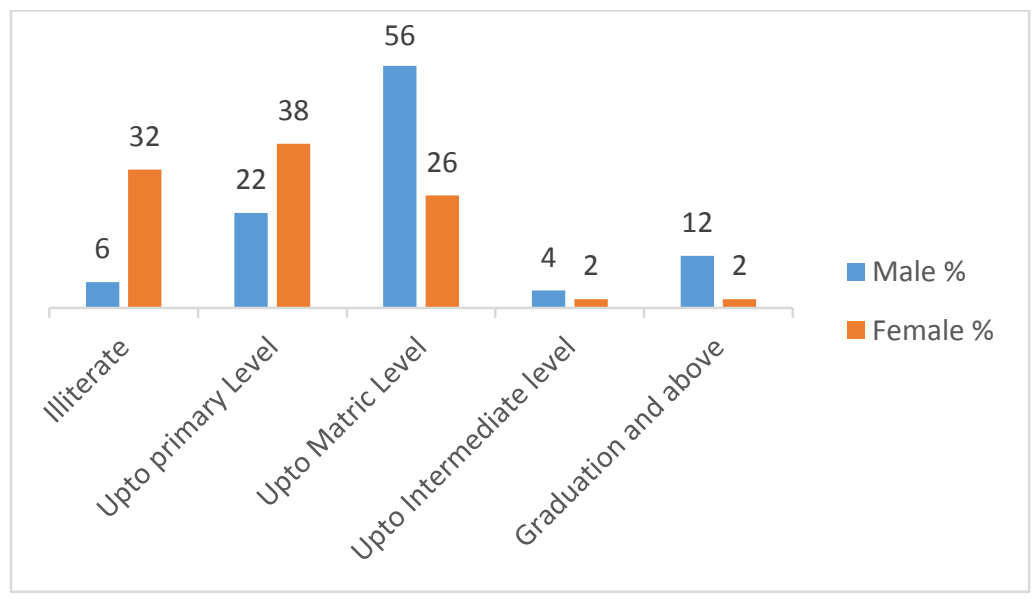

Fig. 1 Educational status of elderly

Table 2: Percentage distribution of elderly by sex and occupation

\begin{tabular}{|c|c|c|c|c|}
\hline Occupational status & \multicolumn{2}{|l|}{ Male } & \multicolumn{2}{|c|}{ Female } \\
\hline & $\mathrm{N}=50$ & $\%$ & $\mathrm{~N}=50$ & $\%$ \\
\hline Agriculture & 15 & 30 & 4 & 8 \\
\hline Business & 21 & 42 & 12 & 24 \\
\hline Government Job & 14 & 28 & 5 & 10 \\
\hline Housewives & 0 & 0 & 29 & 58 \\
\hline
\end{tabular}

The above table shows that most of the female were housewives (58\%) with no other source of income, $10 \%$ were retired government employee, $24 \%$ in small business, $8 \%$ in agriculture while most of the male had personal income. There are $30 \%$ male were in agriculture, $42 \%$ in business and $28 \%$ retired from government job. 


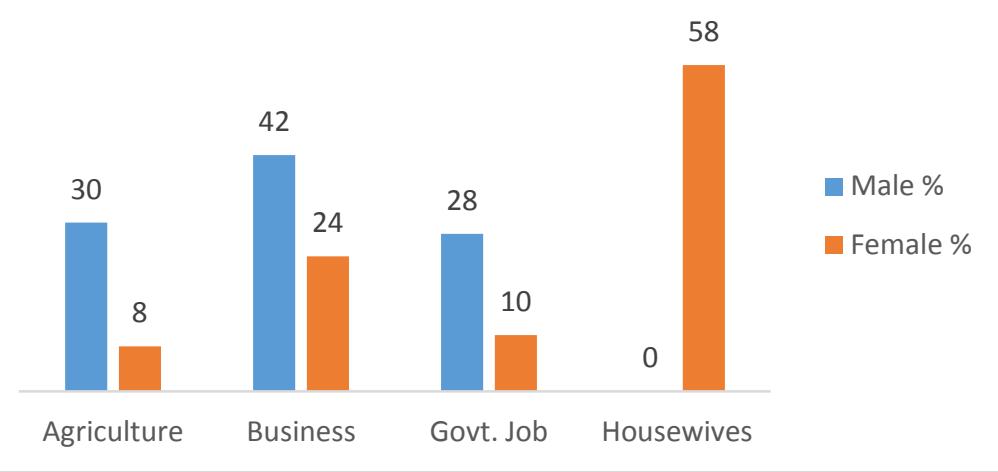

Fig. 2 Occupational status of elderly

Table 3: Percentage distribution of elderly by sex and spousal status

\begin{tabular}{|l|l|l|l|l|}
\hline Spousal status & Male & $\%$ & Female & $\%$ \\
\hline & $\mathrm{N}=50$ & $\%$ & $\mathrm{~N}=50$ & 66 \\
\hline live & 46 & 92 & 33 & 34 \\
\hline Not live & 4 & 8 & 17 & \\
\hline
\end{tabular}

Table 3 shows the spousal status of elderly. Maximum percentages $(92 \%)$ of male elderly were living with their spouse in comparison to female (66\%). Further $8 \%$ male and $34 \%$ female subject's spouse were not live.

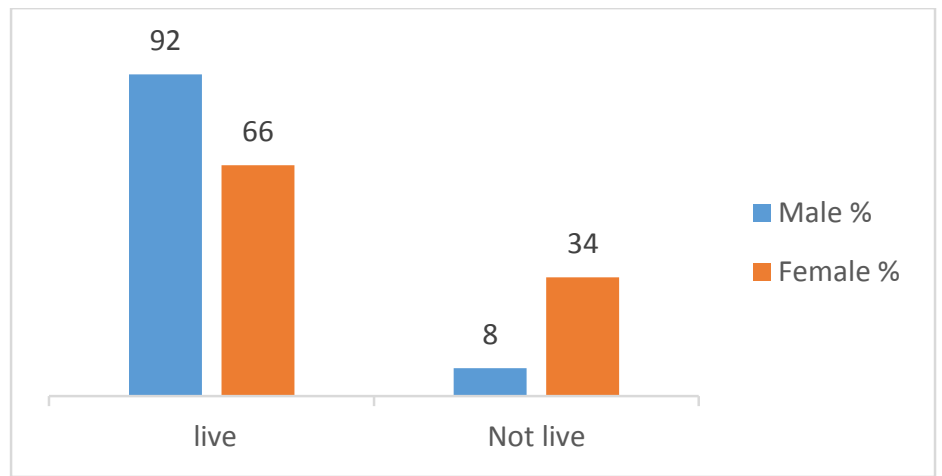

Fig. 3 Spousal status of elderly

Table 4: Percentage distribution of elderly by sex and family type

\begin{tabular}{|l|l|l|l|l|}
\hline Family type & Male & Female & \\
\hline & $\mathrm{N}=50$ & $\%$ & $\mathrm{~N}=50$ & $\%$ \\
\hline Nuclear & 30 & 60 & 41 & 82 \\
\hline Joint & 20 & 40 & 9 & 18 \\
\hline
\end{tabular}

From the above table it is observed that $60 \%$ male and $82 \%$ female were living in nuclear family when $40 \%$ male and $18 \%$ female in joint family.

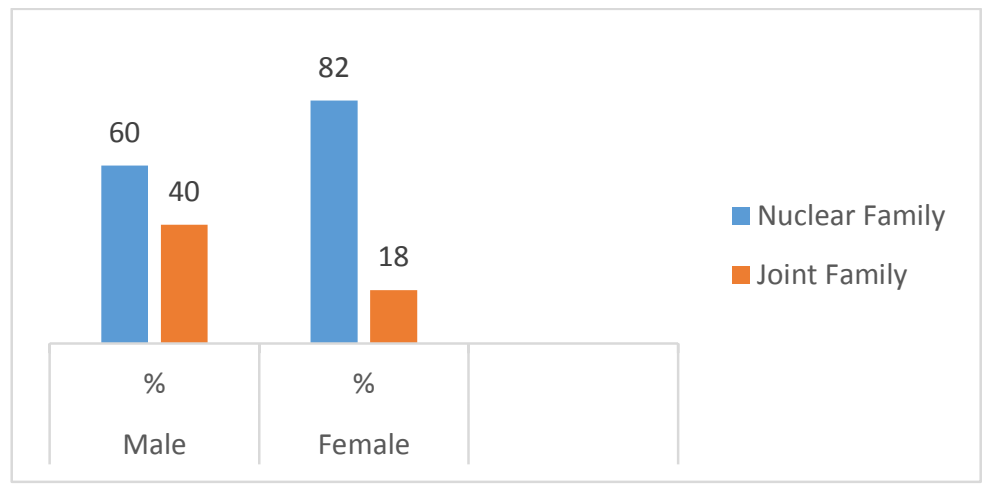

Fig. 4 Elderly living in nuclear and joint family 
Table 5: Gender and six area of adjustment of elderly.

\begin{tabular}{|l|l|l|l|}
\hline Area of Adjustment & Male & Female & t value \\
\hline & Mean & Mean & $0.05 \%$ level \\
\hline Health & 15.28 & 9.4 & $5.970^{*}$ \\
\hline Home & 16.58 & 9.86 & $6.270^{*}$ \\
\hline Social & 14.38 & 8.96 & $7.210^{*}$ \\
\hline Marital & 11.06 & 6.4 & $6.409^{*}$ \\
\hline Emotional & 14 & 8.74 & $5.911^{*}$ \\
\hline Financial & 8.22 & 5.9 & $4.179^{*}$ \\
\hline
\end{tabular}

*Significant at $0.05 \%$ level.

Table 5 shows high significant differences between gender and six areas of adjustment (health, home, social, marital, emotional and financial) of elderly. The mean value shows male persons have higher score in the area of health $($ male $=15.28$, female $=9.4)$, home $($ male $=16.58$, female $=9.86)$, social $($ male $=14.38$, female $=8.96)$, marital $($ male $=11.06$, female $=6.4)$, emotional $($ male $=14$, female $=8.74)$ and in financial $($ male $=8.22$, female $=5.9)$ adjustment than female elderly. The calculated $t$ values of health $(t=5.970)$, home $(t=6.270)$, social $(t=7.210)$, marital $(\mathrm{t}=6.409)$, emotional $(\mathrm{t}=5.911)$ and financial $(\mathrm{t}=4.179)$ are higher than the tabulated value of $\mathrm{t}(\mathrm{t}=$ 1.68). As the calculated values of $t$ are higher than the tabulated value in six area of adjustment at 0.05 levels and 49 degree of freedom, thought concludes that there are significant difference between gender and six area of adjustment.

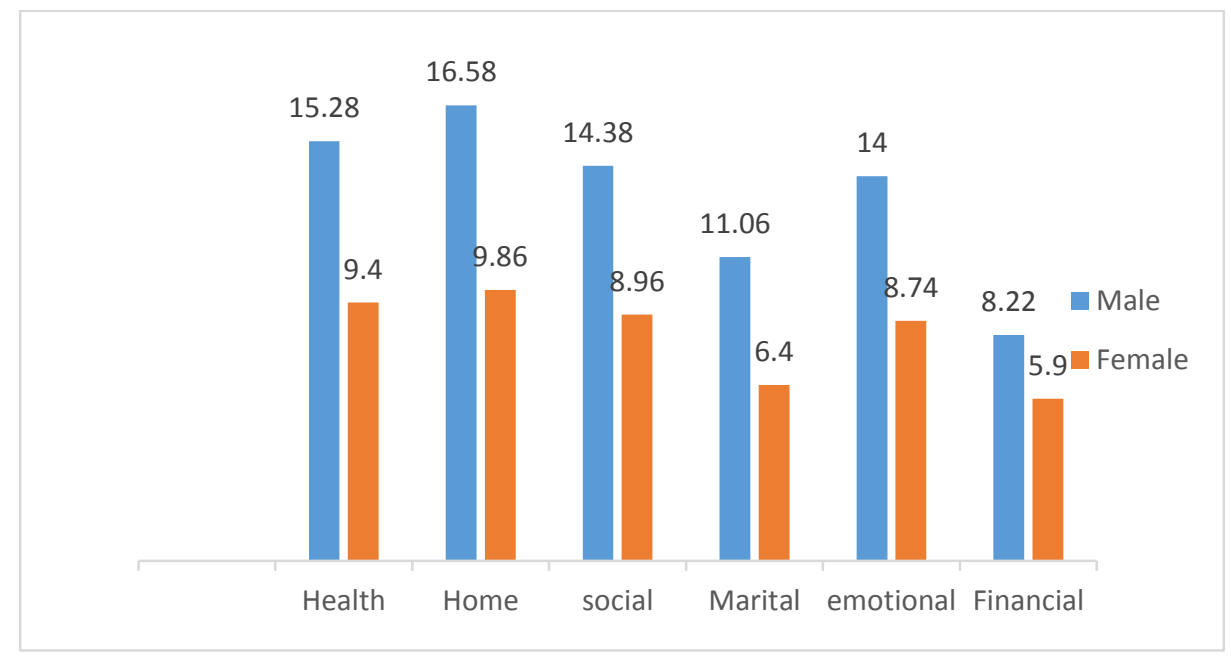

Fig. 5 Six area (health, home, social, marital, emotional and financial) of adjustment of elderly

\section{Discussion and Conclusion}

In the present study, $32 \%$ female were illiterate whereas only $6 \%$ male subjects illiterate. Further $56 \%$ male had studied up to matric level while only $26 \%$ female studied up to matric level. Most of the female elderly were housewives (58\%) whereas $28 \%$ male were retired from government job (getting pension) and $42 \%$ in active business. The numbers of widow were higher (34\%) than the widower $(8 \%)$. Further increased numbers of female elderly (82\%) were in nuclear family than the male $(60 \%)$. Moreover, significant gender differences found in six areas of adjustment of elderly. It was observed that male person had higher level of adjustment in all area than the female elderly. Some of the study reported by power, Gupta and Kohli, (2011), partially support the present study, explore the gender differences on adjustment and anxiety of elderly (50 male and 50 female) between 65 - 75 years. The result revealed that both group had adjustment problem, but significantly higher anxiety and adjustment problem seen among female in health, home and emotional subscales than male.

Besides, demographic trends, breaking of joint family and increased number of nuclear family, male dominated patriarchal society, lack of education, unpaid work at home and in farms, lower life time earnings, lower wages and gender discrimination makes women more vulnerable throughout their lives in rural areas (Capoor, 2008). Keeping this in view the present study was carried out to highlight the problem and its effect on adjustment of elderly. The findings also suggest that government should make plans and policies for promoting better education and employment facilities to the women in rural area. Widow elderly must get priority in 
welfare scheme. There should be a joint effort on the part of government and non-government organization to aware about various plans and scheme meant for the elderly. Further, counseling with the elderly and their family member is needed for better adjustment in old age.

\section{References}

[1] Agewell study, (2011)“Human rights of older persons in India - A National study", Agewell research and advocacy centre, P.2-3.

[2] Bhattacharya, S. and Mukherjee, M. (2013) "Adjustment pattern of people belonging to nuclear family of Calcutta city", Voice of research, 2 (3) P. 1-4.

[3] Capoor, I. (2008) "She too counts: Critical need for gender responsive health care for elderly, presented at the national workshop on gender responsive social protection health security for the elderly", organized by United Nations economic and social commission for Asia and the pacific ministry of social welfare and labour, Mangolia, P 1-22.

[4] Gupta, A. and Kohli, S. (2011) “Adjustment pattern and anxiety in community dwelling elderly: Exploring the gender differences", Journal of mental Health and Human Behavior, 16 (1), P. 29-32.

[5] Kapoor, S.and Kapoor, A.K. (2000) "Socio-Biological Ageing: An inevitable phenomenon", Help Age India-Research and Development Journal, 6, P. 5-10.

[6] Rajasekhar, K. (2013) "Familial relationship of elderly women in rural Andhraradesh India", Paripex- Indian journal of research, 2(7), P. 278- 280.

[7] Hussain, S. and Kaur, J. (1995) "Manual for Samshad - Jasbir old age adjustment inventory", National psychological corporation, Agra, P. 1-13.

[8] Shettar, C.S. and Azim, S. (2011) "Care of elderly in changing Indian family", Social wefare, 58 (7), P. 21-23.

[9] Shukla, P. and Kiron, U.V. (2013) "Subjective happiness among the elderly across various groups",IOSR Journal of humanities and social science (IOSR-JHSS), 13, (6), P. 46-49.

[10] Siva Raju, S. (2000) “Ageing in India: An Overview, in 'Gerontological Social Work in India”, Murli Desai and Siva Raju (Eds.), Delhi, B. R. Publishing Co.

[11] Siva Raju, S (2002) "Meeting the Needs of the Poor and Excluded in India", Situation and Voices, The Older Poor and Excluded in South Africa and India, UNFPA, Population and Development Strategies, 2, P. 93-110.

[12] Siva Raju, S. (2004) "Profile of Elderly and Organisations Working for their Care: A Study in Mumbai", Family Welfare Agency, Mumbai, (Published in Harmony Magazine)

[13] Sujathan, P.K. (2011) "Demographic transition and care for the elderly", Yojana, 55, P. 38-40.

[14] Trivedi, K. andSandilya, V. (2007) "Successful ageing; A study on adjustment and perception of social support of the aged", Excellence in Home science, P. 291-297.

[15] Verma, M.M. (2011) "Elder abuse: The problem and the way out", Socialwefare, 58 (7), 5-11. 